\title{
International Development of Multi-band Pol-InSAR Satellite Sensors for Protecting the Flora and Fauna as well as Natural Land and Coastal Environment within the Equatorial Belt of +/- $23.77^{\circ},+/-18^{\circ},+/-12^{\circ}$ and $+/-8^{\circ}$ Latitude
}

\author{
Wolfgang-Martin Boerner, UIC-ECE CSN-Lab, wmb1uic@yahoo.com, USA \\ Danilo Erricolo, UIC-ECE Andrew Electromagnetics Laboratory, derric1@uic.edu, USA \\ Tadahiro Negishi, UIC-ECE Andrew Electromagnetics Laboratory, t.negishi@gmail.com, USA \\ Rui Yang, UIC-ECE Andrew Electromagnetics Laboratory, ryang22@uic.edu, USA \\ Gerhard Krieger, DLR-HR, Oberpfaffenhofen, gerhard.krieger@dlr.de, Germany \\ Andreas Reigber, DLR-HR, Oberpfaffenhofen, andreas.reigber@dlr.de, Germany \\ Alberto Moreira, DLR-HR Oberpfaffenhofen, alberto.moreira@dlr.de, Germany
}

\begin{abstract}
With the relentless increase in population density, the anthropogenic expansion into natural terrestrial hazard zones has become irreversible resulting in ever more catastrophic disasters, not only in the Asia-Pacific region more so within the entire tropical belt engulfing Mother Earth. Thus not only the IndonesianPacific Islands, so also South America, Africa and back via the Islands of the Indian Ocean to Asia-Pacific, these natural events like volcano eruptions, earthquakes with emerging tsunami, cyclones and severe down pours, humidity and haze have caused havoc, loss of lives, destruction of infrastructure and above all intentional manmade interference resulting in the deterioration of pristine tropical jungle forests. Matters have become so bad that proposals are forthcoming for equating oilpalm and tropical-fruit orchard mono-cultures with pristine tropical jungle habitat by greedy developers mostly exterior to local environmental regions suffering helplessly from it.
\end{abstract}

\section{Introduction}

What is required is around-the-clock local and widearea surveillance and remote sensing of the vegetative cover for which first well designed optical equatorially orbiting satellite sensors had been developed but their successful implementation is failing because of the ever increasing cloud, precipitation, humidity, haze and aerosol cover within the entire equatorial belt of $+/-15^{\circ}$ $\left(\sim 20^{\circ}\right)$ latitude rendering penetration at optical wavelength mostly ineffective. Hence, we must take recourse to microwave sensing, and implement radar and synthetic aperture sensors from air and space operational at day and night independent of weather; and the sensors especially suited are the fully polarimetric PolSAR and interferometric InSAR sensors developed for satellite remote sensing by some of the major SAR technology development centres worldwide.

- Although optical remote sensing including GIS enjoyed great success in the past, satellite optical remote sensing including lidar techniques, has become increasingly ineffective due to increase in ground humidity, haze, fog cloudiness, severe storms, and so on - especially in the equatorial tropical belt and for other similar phenomena also in the polar cap regions.

- Active microwave remote sensing does not suffer like optical propagation from similar deteriorating effects, and SAR sensing is the remedy, penetrating through meteorological covers, volcanic plumes at day and night.

\section{Advantages of ALOS-1 versus ALOS-2 contributions in science and applications for $L$-band re- mote sensing}

JAXA has thus developed multi-modal SAR technology with rigor and drive of which the ALOS-1 and ALOS-2 PolSAR satellite sensors are an excellent and highly appraised example:

- $\quad$ Satisfying the specific needs for the Japanese remote sensing environs, JAXA EORC focused on the use of L-band SAR technology 
with increasing polarization diversity - finally also increasing priority of full PolSAR imaging. Both ALOS-1 and ALOS-2 stand out today to be the top performers as regards narrow swath fixed incidence operation.

- However, the use of the standard planar array antennas limits incidence angle diversity which although may be achieved for limited regional coverage but not for global simultaneous applications, which require beamshaping reflector-type antenna operation.

- ALOS-1 performed very well albeit with limited polarization diversity, whereas ALOS-2 has made available highly improved Quad-Pol imaging with increased bandwidth (resolution); yet both suffer from simultaneous interferometric mode operation.

- Unfortunately the full PolSAR mode operation is at a most deplorable very limited schedule which deserves to be changed radically!

\section{Contributions of CSA Radarsat- $2 \mathrm{C}$-band and future constella- tions}

The Canadian Space Agency CSA developed the RadarSat sensors at C-band as optimal choice for assessing boreal to polar snow/ice-covered environments with the follow-up RADARSAT-2 being fully polarimetric which will be followed by constellation of three similar sensors also providing polarimetric capabilities.

- Satisfying the specific needs of the Canadian Boreal to polar environments C-band was chosen because of its optimal snow/ice assessment

- Fully polarimetric sensing at C-band in addition has been applied to agriculture, forestry and coastal zone environments.

\section{Advantages of F-SAR, TerraSAR-X versus TanDEM-X and its contributions in sci- ence/applications for remote sensing by DLR-HR}

DLR was instrumental in developing foremost X-band airborne and satellite X-band SAR technology, calibration, image acquisition and processing. Recognizing the importance of airborne multi-band fully polarimetric SAR test beds, it developed first the E-SAR and advanced it to F-SAR enabling simultaneous image acquisition at $\mathrm{P} / \mathrm{S} / \mathrm{L} / \mathrm{C} / \mathrm{X}$-bands and soon also at Ka-band. In coordinated efforts with JAXA ALOS-L and CSA RA-
DARSAT-C, the DLR TerraSAR-X and the tandem coflyer TanDEM-X were developed enabling polarimetric, bistatic, interferometric and tomographic satellite image acquisition at highly improved clarity and resolution.

- Satisfying the specific needs for the German and Central European remote sensing environs, DLR focused on the use of X-band SAR technology with diverse polarization diversity - for both airborne with the multi-band F-SAR and satellite TerraSAR-X and TanDEM-X operations.

- $\quad$ The F-SAR is an essential improvement over the original E-SAR which was a multi-band fully polarimetric SAR sensor system but could not operate any bands simultaneously. With the introduction of much more stringent restrictions on aircraft navigational operations by FAA regulations, the former E-SAR operated on the DLR'S DO-228 STOL aircraft had to be replaced by the F-SAR operated on the more advanced DO228-212 aircraft as optimal platform choice satisfying the new regulations. Today, F-SAR is admired worldwide as the supreme multi-band fully polarimetric SAR sensor, desired for executing regional measurement campaigns for comparison of simultaneous multiple band image data acquisitions.

- In developing the Shuttle Radar Topography Mission SRTM in cooperation with NASA and Alenia, DLR contributed the X-band SAR sensor, which then culminated in launching the polarimetric TerraSAR-X satellite and therewith its use for high resolution urban precision imaging for which DLR-IMF developed the advanced image processing algorithms still in use world-wide today.

- TanDEM-X, the first bistatic SAR mission in space which consists of two satellites flying in close formation, is providing a new topographic map of the Earth with accuracy at least 30 times better than the current global available data set achieved with the SRTM sensors, and enabled next to cross/along-track and bistatic-track also tomographic imaging with the new addition of microwave $\mathrm{X}$-band stereo focusing.

- The Tandem-L satellite is being developed with beam-shaping reflector-type antennas for wide swath $(300 \sim 600 \mathrm{~km})$, high resolution (better than $30 \mathrm{~cm}$ ), fully polarimetric (3D) 
imaging, becoming the culmination of the initial X-band satellite SAR developments at DLR, and will herald in a new satellite imaging modality of superior performance capabilities to become a future standard.

- The implementation of the Tandem-L wide swath, high resolution, fully polarimetric sensor concept can easily be expanded to a multiband system simultaneous imaging sensor of wide swath with variable incident angle diversity being especially useful for equatorial belt surveillance and hazard detection.

\section{Approach to equator orbiting single/tandem satellites}

The challenge is thus to develop equatorially orbiting SAR, preferably Pol-InSAR satellite sensors for the desirable $\mathrm{P} / \mathrm{L} / \mathrm{S} / \mathrm{C} / \mathrm{X} / \mathrm{Ka}-m u l t i-b a n d s$, which does pose some technological problems due to the steep incidenceangle illumination on one hand, and because of the fact that the major SAR technology designers reside far outside the equatorial belt whose taxpayers are not being excited about SAR sensor development for the tropical belt anywhere. Therefore, we need to mobilize and draw full responsible attention of the main SAR development centres worldwide such as NASA/JPL, ESA/ESTEC, JAXA/EORC, CSA/SAR, DLR/HR, DSTO/SAR, ISRO/SAC, INPE/SERE plus NTU-Temasek, NCUCSRSR, LAPAN/Rancabungur as well as the United Nations UNESCO, and so on; joining forces and strongly contributing to a viable multi-band general bistatic (including cross/along)-track Pol-InSAR sensor technology, well suited for equatorial monitoring within orbits of the Prime $+/-12^{\circ} \sim 15^{\circ}$ latitude for one-day local imaging, and within the full tropics-latitudinal-belt of $+/-23.7^{\circ}$ for three-day local re-observations.

Once this urgent goal is achieved, local regions could be observed several times daily for along-track wide-swath observations within the inner altitudinal $+/-8^{\circ}$ coverage pertinent also to ocean surface and current assessments; for example, within the Indonesian Archipelago of more than 17000 populated islands and its neighbouring regions of the Philippines with 7000 populated islands, Singapore, Malaysia and Thailand. Relevance to the pertinent transatlantic and transpacific as well as African and American tropical belts are being broached because similar hazards exist. Special emphasis is laid to assess effects of ionospheric interference for P/L/S-band PolInSAR satellite sensor deployment within the tropical belt with participation of pertinent expertise of the UAF-GI at Fairbanks, Alaska, where in addition similar deteriorating meteorological phenomenon for polar cap microwave surveillance and remote sensing are being considered and studied in depth.

\section{Comparison of international PolSAR satellites (DLR Ter- raSAR-X/TanDEM-X, CSA RADARSAT-2 C-band, JAXA ALOS-1/2 L-band, NASA-ISRO NISAR-S/L-band, ESA BIO- MASS P-band) with respect to full polarimetric, interferometric and tomographic capabilities re- quired for realistic complete re- mote sensing of the terrestrial covers and its band extensions}

- $\quad$ Fundamentally, the following performance criteria must be satisfied for optimal multi-modal, multi-band SAR remote sensing: choice of frequency band, polarization, interferometry and tomography as function of incidence.

- $\quad$ The international SAR system operators - for budgetary reasons and regional priorities each chose one band for becoming experts, and at the same time pursuing different modes: narrow-swath fixed incidence using planar array antennas; wide-swath reflector antenna permitting incidence angle diversity; tandem satellite implementation for in situ interferometric and tomographic imaging.

- Several configurations for satellite sensor deployment are assessed based on currently well established narrow-band and rapidly developing wide-band Pol-InSAR sensor technology at X-band and L-band to be complemented in addition by S-band; and later on by P-band and Ka-band fully polarimetric Pol-SAR sensors for simultaneous single-platform observations.

\section{Imaging of full global and future equatorial belt regions including next to current partial accom- plishments expected future in- ternational contributions as one of the leading regional East- Asia/Pacific Pol-InSAR develop- ers}

- For each one complete orbital revolution every point along the fixed orbit can be observed 
about $12 \sim 15$ times; whereas for the current set of polar orbiting SAR satellites the revisittime becomes of the order of $11 \sim 30$ days, and more: Therefore for imaging the equatorial belt region, equator-orbiting satellites are firmly required.

- More so, an implementation of the current planar array ALOS configuration is not satisfactory, and a beam shaping reflector array as currently developed for the ESA-BIOMASS-fullPol P-band, and for the double-band NISAR $\mathrm{S} / \mathrm{L}-$ band is strictly warranted.

- $\quad$ Because geophysical stress-changes are prevalent within the entire equatorial belt, a fully bistatic tandem-satellite approach is in need similar to TanDEM-X and the Tandem-L project - and will soon become the norm for future developments.

\section{Conclusions and international support acquisitions}

The relevance of this challenging still unresolved development of multi-band equatorially orbiting fully polarimetric Pol-InSAR satellite configurations to the entire terrestrial globe will be highlighted. Special attention will be given to generation of global weather phenomena, supply of an ever more relevant stable food base, extraction of mineral and energy resources with its implicit local environmental deterioration, and of more successfully securing bio-diversity. All of these daunting natural hazards of top international priority should justify the immense financial resources required for justifying the pursuit of this timely and urgently to be realized proposal. In retrospect, collaboration with additional international National Research Centers involved in advancing multi-band Pol-InSAR satellite sensors is sincerely desired and so is the financial support from our national, regional and international governmental sponsors - foremost the United Nations.

\section{References}

[1]. W-M. Boerner, International Collaboration on advancing microwave radar remote sensing and stress-change monitoring of the terrestrial covers from space for the benefit of sustaining the biosphere in which we reside. IEICE Global Plaza, 2011

[2] H. Triharjanto From Concept to Early Operation; Lembaga Penerbangan dan Antariksa Nasional. In Proceedings of Indonesian Near-Equatorial
Surveillance Satellite 18th Asia-Pacific Regional Space Agency Forum (APRSAF), Singapore, 2007

[3] W-M. Boerner Future perspectives of multiparameter PolSAR Remote Sensing \& Geo-physical stress-change monitoring within equatorial/subequatorial belts implementing equatorial orbiting single and tandem satellite sensors, Proc. 6-IJJSS2014, Yogyakarta, Java, 2014 October 28 - 30

[4] A. Moreira et al, Tandem-L: A Highly Innovative Bistatic SAR Mission for Global Observation of Dynamic Processes on the Earth's Surface, IEEE GRS-Magazine, Vol.3, no.2, pp.8-23, 2015

[5] A. Reigber, et al. System Status and Calibration of the F-SAR Air-borne SAR Instrument. In Proceeding of IGARSS, pp.1520-1523, Vancouver, BC, Canada, 2011

[6] I. Hajnsek, et al. Indonesian airborne E-SAR radar experiment campaign over tropical forests at $L / P$ - Band of Kalimantan. INDREX II, (Technical Report), 2004

[7] O.R. du Plessis, P. Dereuillet, The ONERA Airborne Multi-Frequency SAR Imaging Systems: RAMSES-NG and SETHI, Proceedings, Int'l. Radar Conference, RADAR-DOI.10.1109/665-1965, 4 pg. 2013

[8] Y. Yamaguchi et al. ALOS-PALSAR QUAD-POL Images. GRS Newsletter, pp. 9-12, 2009

[9] G. Singh et al. Monitoring of the March 11, 2011, Off-Tohoku 9.0 Earthquake with Super-Tsunami Disaster by implementing fully polarimetric high resolution PolSAR techniques. Proceedings of IEEE, vol. 101, no.3, pp.831-846, 2013

[10] W-M. Boerner et al, Development of new multiband equatorially orbiting Pol-InSAR satellite sensors system configurations for varying latitudinal coverage within the tropical belt, Proc. APSAR 2015, Singapore, 2015 September $01-04$

[11] W-M. Boerner et al, Multi-band Equatorially orbiting wide-swath high resolution PolSAR satellite sensors for varying latitudinal belt coverage, Proc. IGARSS 2015, Milano, Italy, 2015 July 26 - 31

\section{Acknowledgement}

This ongoing international project enjoyed the collaboration of many international research centers and institutions - currently too many to be listed here but will certainly be highlighted in the associated full power-point presentation. A special note of thanks is being extended to the organizers of this session, Professors Eric Pottier and Carlos Lopez-Martinez in gratitude for their worldwide open collaboration and leadership in advancing POL-IN-SAR education and verification. 